\title{
NILAI SPIRITUAL DALAM PEMIKIRAN ZA'BA
}

\section{(Spiritual Value in Za'ba Thought)}

Ratna Roshida Ab. Razak

ratna_razak@upm.edu.my

Fakulti Ekologi Manusia, Universiti Putra Malaysia.

Terbit dalam talian (published online): 1 Januari 2021

Sila rujuk: Ratna Roshida Ab. Razak. (2021). Nilai Spiritual dalam Pemikiran Za‘ba. Melayu: Jurnal Antarabangsa Dunia Melayu, 14(1), 141-158.

\begin{abstract}
Abstrak
Za'ba, atau nama sebenarnya Zainal Abidin bin Ahmad bukan sekadar pendeta dan pemikir yang mempunyai mata hati yang tajam, malahan beliau juga merupakan seorang guru spiritual. Hal ini berdasarkan pemikiran beliau yang menyerlahkan makna, tujuan dan nilai hidup yang seharusnya dimiliki oleh setiap manusia yang bergelar Melayu Muslim. Sumbangan beliau kepada masyarakat Melayu sukar ditandingi. Beliau sangat menitikberatkan penghayatan Islam secara menyeluruh dengan memberikan penekanan kepada kesungguhan untuk menggunakan dunia demi kebahagiaan hidup di akhirat. Bagi Za'ba kesalahan dalam berfikir telah menjurus kepada kelemahan dalam membuat sesuatu keputusan dan seterusnya tindakan. Pemikirannya mendahului zaman. Tulisan beliau telah berusia hampir 70 tahun, seperti yang terdapat dalam majalah Qalam yang telah diterbitkan pada 1952, namun inti pati dan topik perbincangannya masih segar dan kekal relevan sehingga ke hari ini. Kesungguhannya memastikan pola pemikiran bangsa Melayu berada pada landasan yang betul lagi benar, seperti yang dianjurkan dalam agama Islam amat jelas kelihatan dalam tulisan beliau. Sehubungan dengan itu, artikel ini bertujuan untuk meneliti dan menganalisis nilai spiritual Za'ba yang terdapat dalam pemikiran melalui tulisannya.
\end{abstract}

Kata Kunci: Za`ba, spiritualiti, pemikiran, melayu, makna, nilai hidup

Abstract

Za 'ba, or his real name Zainal Abidin bin Ahmad is not just a preacher and thinker who has sharp eyes, but also a spiritual teacher. It is based on the idea that emphasizes its meaning, purpose and value of life, which should belong to every human being,

(C) Dewan Bahasa dan Pustaka. 2021. This work is licensed under the term of the Creative Commons Attribution (CC BY) (http://creative commons.org/licenses/by/4.0/)

ISSN 1675-6460 e-ISSN 2682-8049 
MELAYU: JURNAL ANTARABANGSA DUNIA MELAYU JILID 14 BIL. 1 JANUARI 2021

especially to a Malay Muslim. Her contributions to the community is unbeatable. It underlines the general appreciation of Islam by emphasizing a determination to use the world for the happiness of life, here and in the hereafter. For Za'ba, mistakes in thinking lead to weaknesses in making a decision and followed by a bad action. Za'ba's thinking goes beyond times. His writings are almost 70 years old, was found in Qalam magazine which was published in 1952, but the essence and the topics of discussion are still fresh and still relevant until today. The determination of the mindset to ensure that the Malays are on the right track again, as it was recommended in Islam is very evident in his writing. Therefore, this work aims to examine and analyze Za'ba's spiritual values found in his mind through his writings.

Keywords: Za 'ba, spirituality, thought, Malay, meaning and value in life

\section{PENDAHULUAN}

Za‘ba, atau nama sebenarnya Zainal Abidin bin Ahmad (1895-1973) telah dilahirkan di Kampung Kerdas, Batu Kikir, Negeri Sembilan. Beliau bukan sekadar pendeta tetapi pemikir yang mempunyai mata hati yang tajam. Lantaran itu, beliau sentiasa disanjung, dan dikenang sehingga diberi gelaran "pendeta". Maksud kata "pendeta" dalam kamus ialah seorang cendekiawan, cerdik pandai atau mahaguru (Kamus Dewan, 2010). Anugerah tertinggi ini telah diterima semasa Kongres Bahasa dan Persuratan Melayu yang telah diadakan di Johor Bharu dan Singapore pada 1621 September 1956. (Adnan, 1998).

Sumbangan yang diberikan oleh beliau kepada Alam Melayu, khususnya dalam usaha meninggikan kedudukan masyarakat Melayu sukar untuk ditandingi hinggalah ke hari ini. Beliau sangat menitikberatkan perubahan sikap, yang bermula daripada cara berfikir orang Melayu. Kesalahan dalam berfikir inilah menjurus kepada kesalahan membuat sesuatu keputusan dan seterusnya dalam tindakan. Kesungguhannya untuk memastikan pola pemikiran bangsa Melayu berada pada landasan yang betul lagi benar, seperti yang digariskan oleh ajaran Islam itu sendiri amat jelas kelihatan dalam tulisan beliau. Meskipun tulisan beliau berusia hampir 70 tahun, seperti yang terdapat dalam majalah Qalam, diterbitkan pada tahun 1952, namun inti pati dan topik perbincangan yang beliau utarakan masih kekal relevan sehingga ke hari ini.

Penulisan ini berusaha untuk mengetengahkan beberapa idea dan saranan Za`ba berkaitan dengan menghidupkan roh atau daya gerak dalaman, atau disebut juga sebagai rohani atau spiritual. Bagi Za'ba, ajaran Islam mestilah diterjemahkan dalam kehidupan seharian secara yang sebenarnya, tidak hanya mengehadkan terjemahan Islam kepada amalan yang terdapat pada rukun Islam sahaja. Hal ini cukup penting 
sekiranya bangsa Melayu ingin membina kejayaan hidup di dunia dan di akhirat. Aspek penting dan isu pokok yang ingin diluruskan dalam penulisan ini banyak menjurus kepada falsafah, khususnya spiritual. Melalui inti pati pemikiran Za'ba yang berasaskan roh Islam yang mengajak umat Islam, khususnya bangsa Melayu membina kejayaan dan kebaikan dalam erti kata yang sebenar.

Idea dan saranan $\mathrm{Za}^{\text {cb }}$ ba berkaitan dengan ajaran Islam mempunyai hubung kait dengan keseluruhan aspek kehidupan masyarakat Melayu, seperti ekonomi, politik dan sosial. Segalanya berpunca daripada dalam diri individu sendiri, seperti firman Allah dalam Surah ar-Ra'd, ayat 11 yang bermaksud bahawa, "Allah tidak akan mengubah nasib seseorang sehinggalah seseorang itu bangkit untuk melakukan perubahan kepada dirinya sendiri”.

Kontekstual perbincangan ini juga merujuk kegelisahan dan kerisauan cerdik pandai Melayu, khususnya Za'ba, terhadap kemajuan masyarakat Melayu setelah hampir 400 tahun berada di bawah penjajahan kuasa besar Eropah seperti Portugis, Belanda dan Inggeris. Kerisauan dan kecaknaan yang tinggi Za'ba terhadap nasib bangsa telah memperlihatkan beliau sebagai seorang tokoh reformasi atau islah. Hal ini kerana kehidupan politik, ekonomi dan sosial yang dilalui oleh masyarakat Melayu, khususnya dalam era 1920-an, berada dalam keadaan yang sukar.

Za'ba dilahirkan daripada keluarga yang sangat mementingkan ilmu. Bapanya Ahmad bin Ibrahim berketurunan Bugis, manakalanya ibunya Intan Awaluddin berasal daripada suku Minangkabau. Kedua-dua ibu bapanya meletakkan pendidikan sebagai perkara utama dalam kehidupan. Asas didikan agama yang diterimanya daripada ayahandanya sendiri telah berjaya memberikan kekuatan dalaman sehingga beliau berjaya meraih kejayaan sewaktu di sekolah Inggeris tanpa menjejaskan jati dirinya sebagai anak Melayu yang kuat pegangan agamanya.

Meskipun kupasan tentang pemikiran Pendeta $\mathrm{Za}$ 'ba telah banyak dilakukan oleh para pengkaji seperti Nordi Achie, Wan Zailan Kamaruddin, Abdullah Hussein, Adnan $\mathrm{Hj}$ Nawang dan Ermy Azziaty, artikel ini membawa kelainan terutama melalui pendekatan yang digunakan, iaitu dalam aspek spiritual. Aspek spiritual ini didefinisikan sebagai pemilikan makna, tujuan dan nilai hidup melalui tiga jalinan hubungan utama.

\section{KAEDAH}

Artikel ini menggunakan kaedah analisis konseptual melalui teks yang menjadi rujukan utamanya. Kesimpulan secara induktif, deduktif dan deskriptif akan dihasilkan daripada data yang diperoleh daripada sumber ini. Justifikasi pemilihan kaedah ini 
adalah kerana kajian yang dilakukan ini bersifat kajian teks, iaitu meneliti kembali tulisan Za'ba seperti yang terdapat dalam majalah yang pernah ditulis oleh beliau.

Sumber yang digunakan yang terdiri daripada pelbagai penulisan karya $\mathrm{Za}$ 'ba yang telah disusun semula dan dikompilasikan tanpa mengubah apa-apa jua corak penulisan sama ada bahasa mahupun gaya Bahasa. Keaslian yang terdapat dalam penulisan beliau menjadikan pembaca mampu menjiwai apa-apa yang diperkatakan oleh beliau. Kompilasi 15 rencana daripada 28 rencananya yang pernah diterbitkan dalam majalah Qalam sekitar tahun 1952 hingga 1955 telah dibukukan dengan tajuk, Mencapai Ketinggian Dunia Akhirat (2009b), merupakan data utama dalam penulisan ini.

Pembinaan kontekstual perbincangan mempunyai hubung kait dengan idea dan saranan Za'ba, khususnya dalam aspek spiritualiti pemikiran beliau. Hal ini merujuk cara $\mathrm{Za}$ 'ba berfikir untuk mempromosikan kehidupan yang mengandungi makna, tujuan dan nilai hidup berasaskan ajaran agama Islam melalui pemerkasaan hubungan hamba dengan Allah, diri sendiri, manusia dan alam, juga flora dan fauna. Kepentingannya untuk memastikan peranan hati, roh dan akal dapat berfungsi dengan baik dan dizahirkan dalam bentuk adab atau akhlak, juga disebut sebagai perangai. Inilah tema utama dalam perbincangan ini. Kesungguhan Za'ba membicarakan persoalan ini jelas apabila Za'ba menjudulkan bukunya dengan tajuk, "Perangai Bergantung pada Diri Sendiri”.

\section{SPIRITUALITI}

Spiritualiti atau kerohanian didefinisikan sebagai keupayaan untuk memiliki makna, tujuan dan nilai hidup yang jelas. (Danah Zohar, 2000). Pemberian makna, tujuan dan nilai hidup ini juga bergantung pada pandangan semesta, falsafah hidup dan sistem kepercayaan yang dimiliki (Frankl, 1959). Islam, sebuah agama yang berorientasikan Allah dan kehidupan akhirat, meletakkan manusia atas dua tanggungjawab yang utama, iaitu sebagai hamba kepada Allah dan pentadbir demi kesejahteraan alam. Pemilikan makna, tujuan dan nilai hidup hanya dapat diterjemahkan dalam konteks yang sebenar apabila ada hubungan simbiosis yang dijalinkan. Proses menjalinkan hubungan inilah yang memerlukan adab atau akhlak kerana tanpanya, agak sukar hubungan untuk dilestarikan.

Untuk memahami maksud spiritual secara jelas, hakikat kejadian manusia perlu lebih dahulu difahami. Manusia dijadikan daripada tiga komponen utama, iaitu fizikal, intelektual dan spiritual. Berdasarkan pandangan Islam, komponen spiritual ini menempatkan hati atau dipanggil sebagai Qalb dalam bahasa Arab. Pada hati ini letaknya ruh. Ruh (soul) atau jiwa (spirit, yang berasal daripada perkataan Latin, 
spiritus) bermaksud nafas kehidupan. Roh ini ialah kekuatan yang tidak dapat dilihat tetapi berfungsi untuk menghidupkan kehidupan, membesarkan dan memberikan tenaga kepada seseorang, melalui hati yang perlu sentiasa bekerjasama dengan akal (Fethullah, 2011). Hati dan akal meneliti dan merenung pengajaran dan ibrah dalam sesuatu perkara. Hati yang baik (saleem) dan akal yang sempurna amat penting untuk merasai keindahan dalam apa-apa jua perkara dan situasi. Peranan hati yang sentiasa berkolaborasi dengan akal dapat dilihat melalui terhasilnya kebaikan atau nilai murni yang dizahirkan melalui adab, iaitu kesantunan dan kesusilaan yang sekali gus memperlihatkan nilai kemanusiaan yang tinggi, budi (virtues). Proses menzahirkan dan menterjemah nilai murni tersebut adalah melalui pelaksanaan apaapa jua amalan dalam kehidupan dengan bersulamkan akhlak yang mulia, moral atau etika yang terpuji, yang disebut sebagai adab. Adab inilah yang menjadi cerminan bagi komponen spiritual yang dimiliki seseorang individu.

Dalam mendefinisikan spiritual atau kerohanian, sesetengah cendekiawan mentafsirkannya sebagai kuasa dalaman, yang merupakan kuasa sebenar yang mengatur kehidupan seseorang (Frankl, 1959). Kuasa ini dicirikan oleh refleksi, penyataan makna, tujuan dan nilai.

Jika lihat secara mendalam, tema utama yang diangkat Za'ba dalam penulisannya, khususnya dalam majalah Qalam ini ialah tentang sikap orang Melayu dan keperluan untuk mengubahnya. Bagi Za'ba inilah perkara asas untuk membina satu kehidupan yang berjaya dan penuh makna, tujuan dan nilainya. Hal ini dijelaskan sebagaimana katanya:

The crying need throughout the world to-day is for moral and spiritual regeneration. This is my view, can only be achieved through intelligent understanding and observance of the true spirit of religion.

(Catatan Za'ba 15 Disember 1958 di bahagian dalam, halaman tajuk bukunya, Asohan Budi Melalui Islam, dalam Adnan, 1998, hlm. 65)

Daripada apa-apa yang dinyatakan tersebut jelas menunjukkan bahawa keperluan mendesak pada saat ini ialah keperluan membetulkan perihal yang berkaitan dengan moral, iaitu akhlak atau perangai juga tingkah laku. Kesemuanya ini berada dalam salah satu komponen utama kejadian manusia yang disebut sebagai spiritual ataupun rohani.

\section{Makna}

Sejak tahun 1916 lagi, Za'ba banyak mengemukakan pandangan juga luahan rasa apabila melihat banyak masalah yang timbul dan menimpa masyarakat Melayu, 
khususnya dalam aspek pendidikan, ekonomi juga agama. Bagi Za'ba punca kepada permasalahan tersebut dada kaitan dengan kegagalan mereka untuk menterjemahkan Islam dalam bentuk praktikal, dalam kehidupan seharian mereka. Dengan kata lain, mereka gagal menghidupkan roh dengan menepati makna, tujuan dan nilai ajaran Islam. Hal inilah yang dimaksudkan roh atau spiritual dalam beragama, seperti yang dinyatakan oleh beliau:

Umat Islam pada zaman ini sedang dalam kejatuhan dan kemunduran dan kelemahan pada serba serbi- imam [sama ada] pada pihak ilmu dan kepandaian dan kerajaan dan kekuasaan atau pada pihak kesolehan dan ketinggian perangai. Walhasil tiadalah nampak jaya agama yang diperagamakan oleh mereka"

(Utusan Melayu, 18 Februari 1920, dalam Adnan, 1998, hlm. 129)

Za'ba, dengan jelas mengatakan bahawa kelemahan sahsiah, perangai atau adab ialah punca utama kelemahan sesuatu bangsa, khususnya bangsanya sendiri, iaitu bangsa Melayu. Oleh itu, berdasarkan pengertian spiritual yang dijelaskan di atas, ternyata bahawa komponen spiritual perlu diberikan perhatian yang serius agar kekal berada dalam keadaan yang sejahtera dan dizahirkan melalui perilaku dan perangai yang baik, meliputi ketiga-tiga aspek kejadian utama manusia, iaitu fizikal, intelektual dan spiritual.

Za'ba yang pernah memberikan syarahan yang bertajuk "Religion as Spiritual Experience", anjuran The Pure Life Society Corporation pada 6 Ogos 1960, banyak mengingatkan orang-orang Melayu agar memahami makna kedatangan Rasulullah SAW itu adalah untuk menyempurnakan akhlak manusia (Za'ba, 2009a), seiiring dengan firman Allah dalam Surah al-Qalam, ayat 4 yang bermaksud: "Bahawa sesungguhnya engkau Muhammad tentu sekali bersifat dengan sifat-sifat keperangaian yang Maha Besar".

Za'ba pernah menyuarakan pandangan beliau tentang sikap orang Melayu berkaitan ekonomi mereka agar mereka mengambil teladan daripada beberapa institusi ekonomi bangsa lain, khususnya bangsa yang sedia ada di Tanah Melayu. Hal ini penting agar kegiatan ekonomi orang Melayu lebih produktif dan memberikan keuntungan yang besar (Za'ba, 2009a).

Jika ditelusuri daripada penulisan beliau, ternyata bahawa perkara asas yang seharusnya diubah oleh orang Melayu agar dapat keluar daripada kepompong kemiskinan ialah perubahan dalam aspek rohani. Miskin rohani atau spiritual menjadi punca untuk segala jenis kemunduran, sama ada dalam pendidikan, politik, sosial, ekonomi dan lain-lain. 


\section{Tujuan dan Nilai}

Kesejahteraan seseorang individu merujuk keadaan yang baik untuk ketiga-tiga komponen kejadiannya, iaitu intelektual atau minda, fizikal atau jasmani dan spiritual atau rohani, juga disebut sebagai jiwa. Secara fitrah, sekiranya keseimbangan ketigatiga komponen ini tidak dijaga akan mengundang berlakunya kecelaruan yang akan mengakibatkan kedudukan nilai, kebaikan dan adab atau perangai seseorang tergugat. Ukuran nilai (value) sesuatu, sama ada perbuatan atau benda tidak lagi dilihat melalui sudut pandang makna, tujuan dan nilai, tetapi lebih kepada keinginan nafsu yang banyak untuk sesuatu yang bersifat material, yang dimomokkan atas nama kemodenan.

Nilai merupakan antara perkara asas yang dibicarakan oleh $\mathrm{Za}$ 'ba bermula dengan nilai sebuah kehidupan. Secara jelas Za'ba melihat nilai atau harga sebuah kehidupan ini terlalu tinggi kerana hidup ini bukan hanya di dunia, tetapi suatu perjalanan menuju ke akhirat. Untuk membuktikan bahawa kehidupan ini ada nilainya, seseorang perlu melakukan usaha, atau dengan kata lain, ada kerja yang perlu dilakukan selagi hidup di atas muka bumi ini.

Persoalan falsafah hidup dan pandangan alam (worldview) yang diamalkan oleh orang Melayu menjadi minat yang mendalam kepada Za'ba untuk dikaji. Dengan kata lain, Za'ba memerhatikan kelemahan orang Melayu dari aspek dalaman, menerusi cara berfikir orang yang dizahirkan melalui amalan atau budaya hidup mereka. Aspek dalaman, dalam konteks penulisan ini, diistilahkan sebagai spiritualiti (kerohanian), pelengkap kepada dua lagi komponen utama kejadian manusia, iaitu intelektual (akal) dan fizikal (jasmani).

Jika ditelusuri sejarah kedatangan Islam ke alam Melayu sekitar abad ke-13, dengan kejayaan yang dicipta, ternyata Islam yang sampai ke alam Melayu tidak berjaya mencipta kegemilangan, khususnya dalam aspek sains dan teknologi, seperti yang pernah berlaku di Andalusia, sekitar abad ke-8 hingga ke-13. Menurut $\mathrm{Za}$ ‘ba, rahsia kejayaan umat Islam ini seharusnya diteladani dan dipelajari kerana punca utama kejayaan mereka adalah kerana umat Islam ketika itu telah berjaya menterjemahkan Islam yang merupakan sebuah jalan hidup yang bersifat menyeluruh dan berorientasikan Allah dan akhirat. Kejayaan individu dalam ketiga-tiga komponen, iaitu spiritual, intelektual dan fizikal merupakan asas sebuah tamadun hebat yang telah berjaya dibina. Bermula dengan kesejahteraan aspek spiritual yang memberikan penekanan kepada makna, tujuan dan nilai hidup, melalui peranan hati dan akal. atau sering disebut sebagai perihal kerohanian atau kejiwaan, kehebatan akal mampu untuk digunakan untuk mencapai kejayaan yang bersifat lestari ini.

Bagi Za'ba, apa-apa jua bangsa di dunia ini sekiranya mereka berjaya mempertahankan akhlaknya atau disebut juga sebagai perangai atau tingkah laku 
mereka, seperti yang disarankan dalam sistem kepercayaan masing-masing, akan kekallah kedudukan atau kejayaan yang dibina oleh bangsa tersebut. Za'ba ada menyatakan syair yang telah disampaikan oleh Ahmad Shauqi:

Bahawa bangsa-bangsa dalam dunia ini hanyalah wujudnya akhlak jua. Selagi kekal akhlak mereka, kekal pula mereka. Tetapi jika mereka itu hilang akhlak nescaya mereka sendiri pun hilang pula bersama-samanya

(Za'ba, 2009b: 36)

Begitu jugalah sekiranya bangsa Melayu berjaya menzahirkan dan mempertahankan akhlak atau perangainya seperti yang dikehendaki dalam Islam, mereka akan terus kekal dan dihormati oleh semua orang. Ketinggian dan kejatuhan sesebuah kerajaan dan bangsa, banyak bergantung pada perangai rakyat atau individu yang ada dalam sesebuah bangsa tersebut. Oleh sebab itu, peranan akhlak dalam setiap hubungan yang dibina oleh setiap individu merupakan perkara penting yang diberikan penekanan oleh Za'ba.

\section{TIGA HUBUNGAN UTAMA}

Za'ba mempromosikan kehidupan yang mengandungi makna, tujuan dan nilai hidup berasaskan ajaran agama Islam melalui pemerkasaan hubungan dengan Allah, diri sendiri, manusia dan alam, juga flora dan fauna bagi memastikan peranan hati, roh dan akal semuanya dapat berfungsi dengan baik dan dizahirkan dalam bentuk adab atau akhlak, atau juga disebut sebagai perangai.

\section{Hubungan dengan Pencipta}

Hubungan yang rapat yang terjalin antara seorang hamba dengan Tuhannya menunjukkan seseorang mempunyai matlamat yang jelas tentang hala tuju kehidupannya yang sebenar. Za'ba dengan jelas menyatakan hal ini:

Tentang hubungan yang pertama itu ia dikehendaki bertuhan kepada Tuhan yang satu, iaitu Allah SWT, tiada yang lain, dan ia dikehendaki tunduk taat mengikut segala perintah Tuhan yang satu sahaja, iaitu Allah SWT. Tiada yang lain.

(Za'ba, 2009b: 16).

Mempunyai matlamat yang jelas merupakan inti pati kepada pengertian spiritualiti. Za'ba mengetengahkan sebuah hadis yang bermaksud: "Dunia itu 
ialah ladang untuk akhirat" (Za'ba, 2009b). Yang dimaksudkan ladang di sini sudah tentulah sebuah tempat untuk bercucuk tanam atau melakukan sesuatu agar mendapat hasilnya kelak. Kehidupan di akhirat merupakan buah atau hasil daripada kerja yang dilakukan sepanjang kehidupan di dunia ini. Hal ini penting dan seiring dengan firman Allah dalam Surah al-Isra, ayat 72 yang bermaksud: "Barang siapa keadaannya buta dalam dunia ini maka dalam akhirat pun ia buta juga, dan lebih sesat lagi jalannya". Perkataan buta di sini, seperti yang dijelaskan oleh Za'ba merujuk ketidakupayaan mata untuk melihat dengan mata hati, terutamanya dalam konteks menggunakan dunia ini dengan sebaik yang mungkin (Za'ba, 2009a).

Za'ba banyak mengingatkan tentang peranan solat yang dilakukan dengan sempurna menjadikan hubungan seseorang hamba begitu rapat dengan Allah. Hal in cukup penting untuk memastikan kehidupan dapat dijalankan secara terbaik dan juga dapat melindungi umat Islam, khususnya bangsa Melayu daripada terjebak dalam perkara apa tidak diingini. Contohnya terlibat dalam Kristianisasi. Usaha mengkristiankan orang Melayu giat dilaksanakan oleh golongan mubaligh Kristian pada ketika itu. Bukan itu sahaja, malahan keupayaan untuk bangkit menggunakan kehidupan yang dianugerahkan Allah juga memerlukan daya penguat yang terhasil daripada hubungan yang akrab dengan Allah.

Terdapat sesetengah orang Melayu pada waktu itu juga agak culas mengerjakan solat terutama golongan muda yang sebaya dengannya. Orang Melayu juga sangat gemar untuk mempercayai perkara khurafat seperti memakai tangkal. Antara peringatan $\mathrm{Za}$ 'ba tentang solat adalah seperti membandingkan solat seumpama tiket supaya semua amal kebaikan diterima oleh Allah SWT. Tanpa solat maka sia-sialah kebaikan yang dilakukan. Solat mampu menjadikan seseorang selalu mengingati Allah dan mampu menghindari diri daripada melakukan perkara yang boleh mendatangkan kemungkaran, seperti firman Allah dalam Surah al-Ankabut, ayat 45 yang bermaksud: "Dan kerjakanlah sembahyang dengan tetap; bahawasanya sembahyang itu menahan daripada perbuatan yang cemar dan jahat, dan ingat akan Allah itu tentu sekali terbesar daripada sekalian perkara" (Za'ba, 2002).

Islam telah menyediakan panduan dan tatacara yang terbaik tentang cara manusia seharusnya menggunakan kehidupan mereka agar kebaikan yang dilakukan di dunia akan dapat dilestarikan untuk di akhirat kelak. Tatacara kehidupan yang menyeluruh ini, sekiranya benar-benar dipatuhi, mampu menjadikan bangsa Melayu sebagai bangsa yang terhebat seperti yang pernah terjadi kepada umat Islam di bumi Andalusia sekitar abad ke-8 hingga abad ke-13. Walau bagaimanapun, agak malang apabila umat Islam seperti yang dilihat oleh $\mathrm{Za}$ 'ba mendapat pelajaran agama cara selorong sahaja sepanjang usianya tanpa memberikan perhatian yang serius kepada ilmu yang berkaitan dengan dunia ini, khususnya ilmu yang berkaitan dengan sains 
dan teknologi. Saranan untuk bangsa Melayu agar menguasai bidang sains dan teknologi sangat banyak dikupas dalam tulisan beliau yang bertajuk "Kemiskinan Orang Melayu" yang ditulis dalam akhbar Al-Ikhwan, yang diterbitkan pada tahun 1927.

Keadaan umat Islam yang menjadikan Islam sebagai agama yang hanya menekankan perihal rukun, sama ada lima rukun Islam dan enam rukun iman sehingga menjadikan kehidupan hanya menjurus kepada solat, puasa, haji, juga hukum hakam, halal dan haram, berwirid dan berzikir. Bacaan al-Quran hanyalah sekadar bacaan dengan penekanan kepada tajwid tanpa cuba memahami makna atau pesanan yang terdapat di dalamnya. Dengan kata lain al-Quran hanya pada peringkat tilawah (bacaan) dan tidak sampai ke peringkat tadabbur, iaitu peringkat memahami dan mencedok keluar mutiara-mutiara indah bagi menggerakkan manusia agar menjadi umat yang terbaik dalam konteks menggunakan alam dan seluruh isinya atas landasan tanggungjawab manusia sebagai hamba kepada Penciptanya dan pentadbir atau khalifah kepada alam yang didiaminya ini.

Dalam hal ini sekali lagi Za'ba melahirkan rasa kecewa terhadap bangsanya yang dianggap berat sebelah apabila terlalu memfokuskan perkara yang berkaitan dengan ibadah semata-mata:

... sehingga menghinakan dunia dan banyak nikmat kurniaannya Tuhan yang baikbaik menjadi haram kepadanya serta dilarangnya orang lain pula: dan ia hanya sentiasa berkira-kira hendak sembahyang, membaca doa, berwirid dan berzikir sahaja kerjanya siang dan malam, tiada dia mahu dan tiada tahu masuk percampuran dan tidak mengerti sama sekali hal ehwal kehidupan dunia.

(Za'ba, 2009b: 106)

Beliau juga menegaskan bahawa;

... amal ibadah bagi orang Melayu hanyalah terkhas maksudnya kepada kerja-kerja untuk akhirat atau untuk mati sahaja. Tidak termasuk padanya sesuatu yang kenamengena dengan tujuan memperbaik akhlak, membaiki laku perangai, membaiki kelakuan hidup, atau sesuatu untuk mengelokkan sifat-sifat keperangaian dan budi pekerti supaya membetulkan hal ehwal hidup di atas panggung kehidupan di dunia ini bagi faedah dunia dan akhirat kedua-duanya sekali.

(Za'ba, 2009b)

Bagi Za'ba, apa-apa yang dimiliki oleh kebanyakan orang Melayu pada zaman ini, khususnya antara 1920-an hingga 1960-an, hanyalah taklid membuta tuli, iaitu 
ikutan yang tidak disertai dengan berfikir terlebih dahulu, bukannya agama. Mereka juga tidak menggunakan akal secara optimum. Perkara ini seiring dengan sabda Rasulullah SAW apabila Baginda mengatakan; "Agama itu ialah akal dan tidak ada agama bagi orang yang tidak berakal."

Daripada mesejnya jelas menunjukkan bahawa umat Islam tidak boleh sama sekali hanya menjadi pengikut tanpa berfikir terlebih dahulu tentang apa-apa yang ingin dilakukan. Dengan kata lain, berfikir ialah perbuatan yang sangat dituntut dalam Islam. Tidak hairanlah dalam al-Quran, sebanyak 31 ayat yang ada kaitan dengan dengan berfikir, seperti dalam Surah al-Baqarah, ayat 219:

Mereka bertanya kepadamu (Wahai Muhammad) mengenai arak dan judi. Katakanlah: "Pada keduanya ada dosa besar dan ada pula beberapa manfaat bagi manusia tetapi dosa keduanya lebih besar daripada manfaatnya dan mereka bertanya pula kepadamu: Apakah yang mereka akan belanjakan (dermakan)? Katakanlah: "Dermakanlah - apa-apa) yang berlebih dari keperluan (kamu).” Demikianlah Allah menerangkan kepada kamu ayat-ayat-Nya (keterangan-keterangan hukum-Nya) supaya kamu berfikir.

\section{Hubungan dengan Diri Sendiri}

Individu yang berfikir, pastinya mampu untuk memberikan makna, tujuan dan nilai hidup yang dilaluinya bermula dengan hubungan diri sendiri. Hubungan dengan diri sendiri yang dimaksudkan ini ialah keupayaan seseorang individu untuk memperkasakan dirinya dalam konteks yang sebenar, seperti yang telah dijelaskan di atas, iaitu tiga komponen utama kejadian manusia, fizikal, intelektual dan spiritual.

Penekanan utama dalam perbincangan berkaitan dengan hubungan dengan diri sendiri ialah tentang aspek spiritual kerana di sinilah letaknya raja segala anggota tubuh manusia, iaitu hati. Aspek spiritual ini juga disebut sebagai aspek kejiwaan. Dalam usaha menterjemahkan makna, tujuan dan nilai hidup, Za'ba banyak menekankan kepentingan untuk seseorang memajukan diri sendiri yang bermula dengan usaha dan kebolehan diri sendiri. Dengan kata lain keperluan untuk memperkasa (empower) diri sendiri ialah kunci kejayaan seseorang individu. Sesuai dengan matlamat dan tujuan Allah mengutuskan Rasulullah SAW ke dunia ini adalah untuk memperbaik dan menyempurnakan sifat-sifat kemuliaan perangai manusia.

Usaha untuk memperkasakan diri ini juga perlu kepada perubahan cara berfikir kerana tindakan yang dilakukan bermula dengan cara seseorang itu berfikir. Bagi $\mathrm{Za}$ 'ba "kemiskinan perangai berfikir yang tinggi" menjurus kepada kemiskinan tujuan hidup yang mulia. Antara perangai yang sangat ditekankan oleh Za'ba ialah 
perangai bergantung pada keupayaan diri sendiri. Memiliki perangai yang teguh untuk mengejar cita-cita (perserverence), memiliki rasa kebertanggungjawaban yang tinggi (responsible), rajin dan kuat berusaha (industrious). (Za‘ba, 2009a).

Melalui penulisannya, Za'ba memberikan penekanan kepada keperluan memiliki tujuan atau matlamat kehidupan yang jelas. Matlamat ini umpama kompas. Andai salah hala tuju, atau matlamat, maka salahlah proses atau perjalanan ke arah itu. Menggunakan dunia untuk kehidupan yang abadi di akhirat. Hal ini bukan bermaksud untuk memberikan tumpuan hanya kepada kehidupan di akhirat dengan melupakan atau meremehkan usaha yang perlu dilakukan di dunia. Yang menjadi penekanan Za'ba ialah agar orang Melayu berjaya menggunakan dunia sebagai platform atau ladang untuk meraih kenikmatan hidup di akhirat, seperti ayat al-Quran Surah alQasas, ayat 77 yang bermaksud, "Dan carilah olehmu akan negeri akhirat pada barang yang Allah berikan kepadamu. Tetapi jangan kamu lupakan bahagianmu daripada dunia."

Za'ba juga menekankan bahawa sekiranya kejayaan hidup di dunia sahaja yang ingin dicapai, maka itu sebenarnya bukanlah kejayaan. Kejayaan yang sebenar adalah apabila bahagia kehidupannya di alam akhirat lantaran usaha yang telah dilakukan di dunia. Za'ba sangat kecewa melihat keadaan orang Melayu yang dilalaikan dengan keselesaan (bagi anggapan mereka) berada di tanah air sendiri, juga di bawah naungan raja atau sultannya sendiri (Za'ba, 2002). Dalam hal ini, Za'ba tidak melihat bagaimana orang Islam, khususnya bangsa Melayu memaknakan Islam itu sendiri, iaitu satu bentuk penyerahan yang sepenuhnya (total submission) kepada Allah. Segala yang dilakukan adalah kerana Allah dan sentiasa melakukan perkara demi meraih kemuliaan yang bersatu padanya dunia dan akhirat, kerana memahami kejayaan di akhirat bergantung pada tingkah laku, perangai, sifat juga kelakuan hidup semasa hidup di dunia.

Keadaan sosial masyarakat ketika itu masih ramai yang hidup dalam kesusahan. Sebagai contoh, masih ramai yang berbasikal dan berjalan kaki berbanding dengan berkereta seperti keluarga Za'ba yang dikira bernasib baik kerana ayahnya mempunyai kemampuan untuk memiliki kereta sendiri. Dalam hal ini, Za'ba agak berasa sedih apabila masih ramai anak-anak Melayu yang tidak mampu merasai nikmat pendidikan, seperti yang dirasainya. Kesusahan dan kemiskinan terus menguasai diri golongan ini. Mengenangkan keadaan ini, hati kecil Za'ba sentiasa menangis mengenangkan nasib kaumnya yang sukar untuk mendapatkan pendidikan (Za'ba, 2009a).

Mengadakan hubungan diri sendiri juga bagi Za‘ba, membawa maksud bahawa setiap individu perlu terlebih dahulu mengenali dirinya, menyayangi dirinya dan mengetahui cara untuk sentiasa meningkatkan kualiti dirinya, seperti memiliki kemahuan, cita-cita dan keyakinan diri yang tinggi. Bagi Za'ba; "Jika seseorang 
kecil hemahnya dan rendah kemahuan cita-citanya, nescaya ia hanya akan berpuas hati dengan mendapat perkara-perkara yang sesuai dengan kedudukan dirinya yang rendah itu sahaja, tiada lebih tinggi" (Za'ba, 2009b: 25)

Secara psikologi, pemilikan hemah, azam atau daya juang yang tinggi merupakan satu keperluan penting bagi setiap individu. Hal ini kerana hemah, azam, semangat untuk hidup atau daya juang yang tinggi diperlukan untuk individu membuat pilihan dan mengurus kehidupan mereka dengan baik di samping menjadi faktor penting kepada kesejahteraan individu itu sendiri.

Za'ba banyak mengetengahkan idea utama tentang keperluan memiliki ketinggian cita-cita dan keazaman, seperti yang pernah diutarakan oleh pemimpin utama dalam sejarah Islam. Sebagai contoh, Sayidina Muawiyah, seorang panglima Islam pernah berkata bahawa; "Tumpukan hatimu kepada darjah-darjah ketinggian dalam segala pekerjaan yang mulia supaya dapat kamu capai akan darjah itu" (Za'ba, 2009b). Dalam tulisan yang sama, Za'ba menjelaskan kata-kata seorang penyair Arab:

"Segala jenis ketinggian itu mengikut kadar sebanyak mana susah payah yang ditanggung dan dikerjakan bagi mencapainya. Maka barang siapa suka hendak mendapat ketinggian, kenalah ia berjaga pada malam-malam hari bagi meneruskan kerjanya"

Ketinggian yang dimaksudkan di sini mengikut huraian Za'ba ialah berkaitan hasil yang terbaik, sama ada yang bersifat duniawi atau ukhrawi atau akhirat. Za'ba menegaskan kepentingan melaksanakan tanggungjawab yang terdapat pada diri sendiri kerana faedah itu akan kembali kepada diri sendiri juga. Selain itu, melaksanakan tanggungjawab terhadap diri sendiri juga memperlihatkan kesediaan seseorang individu untuk mempertahankan sifat kemuliaan dan kehormatan kejadiannya sebagai makhluk yang telah dijadikan dengan sebaik-baik kejadian, iaitu dianugerahi akal dan fikiran. Dalam perkara ini Za'ba membahagikan pelaksanaan tanggungjawab terhadap diri sendiri kepada dua bahagian, iaitu aspek luaran dan aspek dalaman.

Aspek luaran atau disebut juga sebagai fizikal atau jasmani merujuk tubuh badan seseorang individu itu sendiri. Hal ini amat penting untuk menghindari dirinya daripada apa-apa jua penyakit kerana:

Demikian ini nyatalah supaya ia sendiri terpelihara daripada sengsara mengidap sakit sendirinya; supaya orang lain terpelihara jangan jadi susah pula dengan sebab ia sakit itu, dan akhirnya supaya orang lain atau orang ramai yang hidup di kelilingnya jangan dijangkiti pula oleh penyakitnya itu hingga menjadi kesusahan yang merebak dan kerugian yang umum. 
Za'ba seterusnya menegaskan bahawa menjadi keperluan untuk setiap individu menjaga tubuh badan sendiri supaya kekal sihat. Badan yang baik juga melahirkan akal yang baik. Za'ba menegaskan bahawa Islam sangat menekankan tentang aspek kebersihan fizikal kerana kebersihan mempunyai kaitan yang sangat rapat dengan kebahagiaan. Bagi Za'ba; "Jika adapun kekayaan, kemuliaan, kebesaran- tiadalah apa gunanya dan nikmatnya kepada orang yang tiada sihat itu” (Za‘ba, 2009b: 61).

Aspek dalaman atau juga disebut sebagai aspek spiritual atau rohani merupakan komponen yang tidak boleh dilihat secara mata kasar. Antara organ utamanya ialah hati. Sifat hati ini, sama ada baik atau sebaliknya dizahirkan melalui budi pekerti atau perangainya. Bagi Za'ba aspek rohani, jiwa atau spiritual ini lebih penting kerana kesakitan yang dihadapi oleh aspek ini boleh mendatangkan musibah yang besar kepada seseorang. Untuk kesejahteraan aspek dalaman inilah yang memerlukan ilmu agama, kerana daripadanya dibekalkan manusia cara aspek dalaman ini dihidupkan dan disuburkan. Za'ba juga menegaskan bahawa ilmu agama ini bukan hanya menjurus kepada aspek ibadah seperti puasa, solat, wirid semata-mata. Aspek yang lebih penting ialah cara menggunakan ilmu agama untuk menjadikan seseorang itu berjaya menggunakan dunia dengan terbaik sehingga dapat meneruskan kejayaan hidupnya di alam akhirat. Za'ba mengingatkan bahawa dunia ini ialah ladang untuk akhirat. Oleh itu, ladang perlu dikerjakan terlebih dahulu agar dapat merasai buah atau hasil dalam kehidupan akhirat nanti.

Za'ba juga ada menzahirkan kekecewaan terhadap orang Melayu yang tidak mempunyai kepercayaan pada diri sendiri dan kekurangan kesungguhan, sedangkan inilah kunci kekuatan seseorang individu. Hal ini seperti yang telah dijelaskannya bahawa tidak akan teguh dalam cita-cita, kekurangan tanggungjawab diri sendiri, ketidakteguhan terhadap kewajipan yang patut dilakukan, tidak menepati masa, tidak bekerja kuat, tidak rela betkorban, tidak memiliki sifat kebajikan atau kemasyarakatan serta kelemahan dalam semangat cinta tanah air (Za'ba, 1998).

Jika ditelusuri tulisan Za'ba ternyata beliau banyak mengingatkan masyarakat Melayu agar bangkit berusaha dengan sedaya upaya, menggunakan ruang masa dan kesihatan yang ada untuk melakukan sesuatu terutama untuk memajukan diri yang telah lama direhatkan oleh pihak penjajah, sekitar 147 tahun lamanya, iaitu bermula pada 1810 hinggalah 1957. Za'ba mengemukakan hadis Rasulullah SAW; "Orang yang berusaha mencari kehidupannya sendiri ialah kekasih Allah".

Za'ba juga merupakan seorang ahli tasawuf atau guru spiritual dalam konteks yang sebenar. Hamka ada mengatakan:

Tasawuf itu membersihkan jiwa, mendidik dan mempertinggikan darjat budi, menepiskan segala ketamakan dan kerakusan. Sentiasa menghidupkan semangat 
1slam, iaitu semangat berjuang, semangat berkorban, bekerja dan bukan semangat lambat dan lembap.

(Hamka, 2017: 5).

Dengan ilmu tasawuf dan spiritualitinya, maka Za'ba memberikan penekanan utama terhadap aspek hati dan budi dalam usaha mendidik masyarakat. Hal ini kerana kesejahteraan dalaman akan terzahir pada luaran, iaitu pada akhlak atau budi pekerti. Untuk memastikan komponen ini hidup subur, proses menuntut ilmu adalah sesuatu yang sangat diperlukan. Za'ba mengingatkan bahawa Rasulullah SAW pernah bersabda yang bermaksud' "Pengetahuan yang halus atau falsafah itu ialah seolah-olah binatang sesat kepunyaan orang mukmin: dipungutnya (ditangkapnya) akan dia di mana ia berjumpa." (Za'ba, 2009b).

Dalam banyak jenis ilmu yang dimiliki, yang penting bagi Za'ba ialah ilmu yang meninggikan budi pekerti atau akhlak. Perkara ini seiring dengan matlamat mengapa Rasulullah diutuskan ke muka bumi, iaitu untuk menyempurnakan akhlak manusia dalam konteks penyempurnaan yang sebenar. Ilmu yang seterusnya perlu dimiliki oleh setiap individu ialah ilmu untuk kegunaan kehidupan dan kesejahteraan manusia, sesuai dengan peranan manusia sebagai pentadbir alam.

Bergantung pada diri sendiri merupakan antara perkara yang sangat ditekankan oleh Za'ba kerana tuntutan ini sangat dituntut dalam Islam seperti firman Allah dalam Surah al-Muddathir, ayat 38 yang bermaksud: "Setiap orang bertanggungjawab atas apa yang dilakukannya." Saranan ini seiring dengan ajaran Islam yang menuntut umatnya agar bergantung hanya kepada Allah, seperti dijelaskan Za'ba (1958):

Tiap-tiap orang yang hendak mencapai ketinggiannya baik dunia atau akhirat wajiblah tinggi hemahnya dan mulia cita-citanya, kuat beramal dan bekerja kuat bergantung pada usaha sendiri dan kebolehan sendiri; dan tidak suka berharap kepada pertolongan orang dan sokongan orang walau daripada orang yang terkeatas.

Jika ditelusuri penulisannya seperti yang terdapat dalam Qalam, ternyata, pesanan beliau berkaitan dengan keperluan untuk memperkasakan hubungan dengan diri sendiri ini sangat banyak. Hal ini menjelaskan kepada kita bahawa kesungguhan dan kejujuran $\mathrm{Za}$ 'ba untuk memastikan setiap individu Melayu untuk bangkit dan melakukan kerja dengan diri sendiri, tidak bergantung kepada pertolongan orang lain, kecuali kepada Allah. Beliau juga mengingatkan agar sentiasa mempunyai keyakinan dan kepercayaan pada kebolehan diri sendiri. Fikirlah sendiri, pertimbanglah sesuatu dengan sendiri dan jangan hanya menjadi mengikut semata-mata tanpa berfikir terlebih dahulu tentang apa-apa yang diikuti. Percaya kepada kebolehan diri sendiri yang 
dianugerahkan Allah kepadanya antara lain ialah sentiasa menghormati diri sendiri, berani menentang kesusahan dan bahaya, berani mara ke hadapan, bijak mengurus kewangan, pandai mengurus masa, sentiasa ingat akan kehebatan dan kekuasaan Allah dan akhirnya jangan mudah untuk merasa selesa dengan apa yang ada.

\section{Hubungan Sesama Manusia.}

Za'ba mengingatkan tentang kedudukan manusia di sisi Allah adalah sama. Yang membezakan mereka ialah tahap ketakwaan seperti yang dijelaskannya: "Ukuran lebih atau kurang darjat di hadapan Allah itu hanya bergantung kepada satu pengukur sahaja, iaitu siapa yang lebih menyempurnakan kewajipannya kepada Allah. Maka dialah yang terlebih mulia pada Allah" (Za‘ba, 2009b). Menjalinkan hubungan sesama manusia ini bukanlah sekadar bermaksud berbaik-baik atau saling kenal-mengenali. Yang disarankan adalah untuk saling tolong-menolong atau bantu-membantu, terutama bagi mereka yang memerlukan bantuan. Melalui pertolongan yang diberikan akan terserlah kehebatan yang sebenar, kerana bagi Za'ba, kebaikan yang dilakukan kepada orang lain merupakan perbuatan jariah atau pusaka alam yang akan kekal berjasa terutama apabila seseorang kembali ke laman abadi. Kebaikan kepada orang lain juga mampu memberikan faedah yang besar kepada seluruh manusia.

Za'ba amat menekankan kepentingan untuk memikirkan tentang keadaan atau hal orang lain, bukan sekadar berkira-kira untuk tujuan diri sendiri sahaja. Bukanlah bermaksud bahawa mengambil tahu hal orang dalam bentuk yang negatif, namun lebih kepada untuk memastikan keadaan orang lain sentiasa berada dalam keadaan yang baik.

Seorang yang sudah dewasa dan sudah dapat pelajaran cara Eropah sahaja, jika keadaan hidupnya sentiasa berkira-kira hendak kaya, hendak senang bagi dirinya sendiri, hendak bersuka-suka dan bersedap-sedap, atau tujuan hidupnya hanya hendak dapat pangkat dan nama dan harta sahaja dalam dunia ini, dengan tiada terlintas di dalam hatinya hendak memperbaiki pihak-pihak dalam dirinya seperti pihak batin, pihak otak, pihak fikiran, pihak jiwa dan rohani, pihak membuat kebaikan yang sebenar dan jasa baik yang sebenar - maka yang demikian ialah sebab pengaruh pelajarannya yang sepihak sahaja itu menjadikan pandangannya berat sebelah, tidak ia mengerti cukup darihal pihak yang satu lagi, yang lebih halus, lebih tinggi dan lebih mulia.

(Za'ba, 2009b: 117)

Dalam hal ini juga, jika dilihat dalam misi dan visi perjuangannya, beliau sangat menitikberatkan kepentingan berpersatuan, bekerjasama atau berorganisasi dalam usaha untuk memajukan bangsa Melayu di tanah airnya sendiri. (Adnan, 1998). 
Hal ini jelas menunjukkan bahawa beliau sangat mementingkan hubungan sesama manusia, khususnya sesama bangsanya sendiri.

\section{Hubungan dengan Makhluk yang Selain daripada Manusia, Khususnya Alam Sekitar Termasuklah Flora dan Fauna}

Perasaan kasih sayang bukan hanya sesama manusia, tetapi juga kepada makhluk selain manusia. Za'ba ada menjelaskan bahawa amat perlu bagi ibu bapa untuk mengajar anak-anak tentang kasihnya haiwan atau serangga, kerana; "tiada siapa mengingatkan dia akan kezalimannya itu, tidak diajar oleh ibu bapanya atau guru Qurannya fasal perangai kasihan dan jangan aniaya kepada makhluk Tuhan”. (Za‘ba, 2009b: 32). Meskipun aspek hubungan dengan unsur alam ini tidak banyak dizahirkan dalam penulisannya, yang pasti hubungannya tetap ada, terutama dalam keupayaannya menghasilkan sajak atau syair yang sangat puitis.

Za'ba sering mengingatkan masyarakat Melayu ketika itu untuk memberanikan diri menggunakan alam sebagai medan untuk penerokaan ilmu dengan mencari rahsia dan tabiat kejadian setiap isi alam itu. Bagi Za'ba hal ini bertepatan sekali dengan firman Allah dalam Surah al-Jathiyah, ayat 13 yang bermaksud: "Dan telah diperhambakanNya kepada kamu (manusia) segala apa yang ada di langit dan segala apa yang ada di bumi sekalian sebagai kurniaan daripadanya". Dan disebut lagi sebagaimana dalam Surah al Baqarah, ayat 29 yang bermaksud: "Dialah Tuhan yang telah menjadikan bagi kegunaan kamu apa-apa yang ada di bumi ini sekaliannya” (Za‘ba, 2009b).

\section{KESIMPULAN}

Mendalami pemikiran Za'ba menerusi penulisan yang dihasilkan, dengan jelas memperlihatkan dirinya sebagai individu yang mempunyai tahap spiritualiti yang tinggi seperti dijelaskan melalui tiga hubungan utama yang ditekankannya. Beliau merupakan seorang yang jelas akan makna, tujuan dan nilai hidup, hubungan dengan Pencipta, diri sendiri, sesama manusia dan dengan makhluk selain manusia, serta alam. Beliau seorang yang jelas akan matlamat akhir sebuah kehidupan, iaitu akhirat. Untuk menghasilkan perhubungan yang memberikan makna, sudah pasti memerlukan unsur-unsur penting untuk menggerakkannya. Unsur tersebut mengikut pandangan Islam ialah hati yang bekerjasama dengan akal. Manusia sebagai makhluk yang terbaik dan sempurna kejadiannya telah dianugerahkan Allah dengan akal. Akal bertindak umpama menteri, manakala hati bertindak seperti raja, yang berperanan menentukan sama ada apa-apa yang disarankan oleh akal perlu dilaksanakan atau sebaliknya. Oleh

sebab dalam Islam hati merupakan raja kepada anggota, sekiranya baik hati seseorang 
manusia itu, maka baiklah keseluruhan dirinya, dan sekiranya rosak hati seseorang manusia itu, maka rosaklah keseluruhan dirinya.

Za'ba berusaha menyedarkan bangsa Melayu untuk bangkit menjadi bangsa yang berjaya dalam konteks yang sebenar, iaitu berjaya di dunia dan di akhirat. Komponen

spiritualnya yang sejahtera, penuh keikhlasan dan kejujuran, sangat jelas terpancar dalam penulisannya dan dilestarikan sehingga akhir hayatnya.

\section{RUJUKAN}

Abdul Hamid, et al. (2008). Memartabatkan warisan Pendeta Za'ba. Universiti Sultan Idris, Tanjung Malim.

Adnan Hj Nawang. (1998). Za 'ba dan Melayu. Kuala Lumpur: Berita Publishing Sendirian Berhad.

Abdullah Hussain \& Khalid M. Hussain. (2000) Pendeta Za 'ba dalam kenangan. Kuala Lumpur: Dewan Bahasa dan Pustala

Danah Zohar \& Ian Marshall (2000). Connecting with our spiritual intelligence. London: Bloosmbury Publishing.

Rozali, Ermy Azziaty. (2017). 'Jalan Keselamatan Bagi Orang-Orang Melayu' : Pemikiran Za'ba bagi memajukan pendidikan dan ekonomi pada tahun 1920-an. SEJARAH: Journal of the Department of History, [S.1.], v. 18, n. 18, nov. 2017. ISSN 1985-0611. Diakses daripada_https://ejournal.um.edu.my/index.php/SEJARAH/article/view/9218

Frankl, V. (1959). Man's search for meaning. New York: Random House. Fethullah Gullen. (2012). The Statue of our souls. Somerset: The Light Inc.

Hamka (2017). Tasawwuf moden. Selangor: PTS Media Group

Nordi Achie. (2006). Pemikrian Za ba dalam falsafah takdir (1932). Sabah: Penerbit UMS. Wan Abdul Kadir, (Ed). (1996). 100 Tahun Za 'ba: Za 'ba pejuang bangsa. Kuala Lumpur: Jabatan Penerbitan Universiti Malaya.

Wan Ali, Wan Zailan Kamaruddin. (1996). Pendita Za'ba: Pemikirannya mengenai Islam dan Melayu. Dlm. 100 Tahun Za'ba: Za'ba Pejuang Bangsa. Kuala Lumpur: Akademi Pengajian Melayu, Universiti Malaya, pp. 285-308.

Zainal Abidin Ahmad. (Za‘ba), (1958). Asohan budi Menerusi Islam. Kuala Lumpur: H.M. Shah Enterprise.

Zainal Abidin Ahmad (Za‘ba). (2002). Ilmu mengarang Melayu, Kuala Lumpur: Dewan Bahasa dan Pustaka.

Zainal Abidin Ahmad (Za'ba). (2009a). Perangai bergantung pada diri sendiri (edisi khas). Kuala Lumpur: Dewan Bahasa dan Pustaka.

Zainal Abidin Ahmad (Za‘ba). (2009b). Mencapai ketinggian dunia akhirat. Kuala Lumpur: Dewan Bahasa dan Pustaka.

Tarikh Peroleh (received): 30 Mac 2020

Tarikh Terima (accepted): 21 Disember 2020 